\title{
Development of Advanced Interspecific-bridge Lines among Cucurbita pepo, C. maxima, and $C$. moschata
}

\author{
Qi Zhang ${ }^{1,4}$, Enda Y $\mathbf{u}^{2}$, and Andy Medina ${ }^{3}$ \\ Hollar Seeds, Plant Breeding, P.O. Box 106, 18875 Highway 50 East, Rocky \\ Ford, CO 81067
}

Additional index words. interspecific-bridge lines, crossing compatibility, breeding, Cucurbita genus

\begin{abstract}
Interspecific hybridization among the three most economically important cultivated species of Cucurbita spp., Cucurbita pepo, $C$. moschata, and $C$. maxima can be made but not readily. By means of various pollination measures, different mating systems, and varying selection methods, nine advanced interspecific-bridge lines were developed, in which the crossing barrier among the species and the male sterility of the $F_{1}$ and subsequent generations were overcome over a 12-year period from 1999 through 2011. Despite the considerable influence of parental cultigens and environmental factors on the incompatibility of interspecific crosses, the plant and population compatibility significantly increased when a backcross with a recurrent parent in the same species or a multiple-way cross with a parent in the different species was made. As the generations advanced, the percentage of fertile seeds (PFS) significantly increased in all the sib- and self-families. The four advanced interspecific-bridge lines out of nine not only have gained the normal crossability of interspecific hybridization, but also could eliminate the sexual obstacles of the subsequent generations. The results demonstrate that a two- or three-species bridge line with crossing compatibility can be created by two- or threespecies recombination and continuous selection. More importantly, the breakthrough of the advanced interspecific-bridge lines could provide a powerful platform for breeders to transfer favorable traits freely among the species and create more valuable and unique types or varieties through a conventional breeding process.
\end{abstract}

Cucurbita pepo, C. moschata, and C. maxima are the most economically important three (out of five) cultivated species within the Cucurbita genus that include squashes, pumpkins, and gourds, which represent several species in the same crop (Blanca et al., 2011; Robinson, 1995). These species are remarkably diverse in morphology, disease resistance, and environmental adaptability (Loy, 2004; Saade and Hernandez, 1994; Whitaker and Bemis, 1964). For a long time, breeders have attempted to use variability in the genus for crop improvement through interspecific breeding yet overcoming crossing barriers, the male sterility, and incompatibility of the interspecific $F_{1}$ and early succeeding generations of distant crosses has been a major challenge for Cucurbit breeders (Chekalina, 1974; Hiroshi, 1963; Rhodes, 1959; Shifriss, 1987; Wall, 1961). Based on the species crossability, Whitaker and Davis (1962) concluded that $C$. moschata occupies a central position among the annual species and can be

\footnotetext{
Received for publication 10 Jan. 2012. Accepted for publication 28 Feb. 2012.

${ }^{1}$ Plant Breeder.

${ }^{2}$ Research Assistant.

${ }^{3}$ President of Hollar Seeds.

${ }^{4}$ To whom reprint requests should be addressed; e-mail qizhang@hollarseeds.com.
}

crossed with difficulty with $C$. maxima, $C$. pepo, and $C$. mixta. Fertile seeds from a series of interspecific crosses were successfully obtained in the past few decades (Baggett, 1979; Castetter, 1930; Erwin and Haber, 1929; Kanda, 1984; Shifriss, 1987; Wall, 1961). While making the crosses, fruit set is generally quite low for many crosses and the occasional fruit produced may have few seed or none (Baggett, 1979; Cheng et al., 2002; Robinson, 1999). To obtain fruits and fertile seeds from the $\mathrm{F}_{1}$ plants of interspecific crosses, additional techniques like repeated pollination, bud pollination, mixed pollen pollination, embryo culture and /or amphidiploidy, and the adjustment of florescence and environmental conditions are frequently used (Bemis, 1973; Cheng et al., 2002; Hiroshi, 1963; Shifriss, 1987).

To overcome species barriers, a wild species (for example, C. argyrosperma) with a wide cross compatibility have been used as a genetic bridge to transfer genes between other less-compatible cultivated species (McCandless, 1998; Wessel-Beaver et al., 2004) or used to create genetic bridge lines by crossing with an interspecific $F_{1}$ (Chetelat and DeVerna, 1991; Finkers et al., 2007). A sterile $F_{1}$ from two distant species can be retrieved by embryo and ovule culture and directly used as a bridge line for gene transfer (Pico et al., 2000; Poysa, 1990; Wang et al., 2002) or subsequently chromosome doubled to produce a fertile amphidiploid. This amphidiploid or the derivatives therefrom offer a possible genetic bridge between the incompatible species (Chen et al., 2011; Parisi et al., 2001; Staub, 2002). However, although a wild species, interspecific $\mathrm{F}_{1}$, amphidiploidy, or induced polyploidy as a genetic bridge plays an important role in overcoming species barriers and the male sterility of interspecific $F_{1}$ for gene transfer, none of these genetic bridges can solve the male sterile, incompatible, and infertile problems in the later generations (Stebbins, 1956; Wang et al., 2002). Moreover, during the transfer of important characteristics with the bridges, unfavorably species-specific traits are frequently carried along to subsequent populations from initially interspecific hybridization (Whitaker and Robinson, 1986). Nevertheless, the disadvantages may be removed by intervarietal hybridization and selection (Munoz et al., 2004; Singh et al., 2009; Stebbins, 1956).

The objective of this study is to develop interspecific inbred lines with normal compatibility by varietal recombination among the three species and successive selection through different mating and selection methods. Meanwhile, some important traits such as plant habits, fruit types, multiple disease resistance, and heat and cold tolerance are integrated into the lines for the purpose of developing new Cucurbit types or varieties. To realize the objective, the removal of the male sterility and sexual incompatibility of interspecific $F_{1}$ and subsequent generations was determined as a main task in this study.

\section{Materials and Methods}

The breeding materials used in this study included $\mathrm{S} 179$ (C. pepo, spp. pepo), 3112 PMR (C. pepo, spp. pepo), H7B (C. реро, spp. pepo), Sugar Loaf (C. pepo, spp. ovifera), Neck Pumpkin (C. moschata), Argonaut $(C$. moschata), Buttercup (C. maxima), and Rouge Vif D'Etamps (C. maxima). Among the first four, S179 is a long, straight Lebanese marrow line that was used as an interspecific donor of the neck straightness to correct the curviness of the long butternut cultivars; 3112PMR represents a short marrow zucchini line with zucchini yellow mosaic virus, watermelon mosaic virus, and PMR. H7B is a PMR pumpkin, which also tolerates Charcoal Rot (Macrophamina phaseolina), Pythium Root Rot (Pythium aphyanidermatum), and fusarium wilt (Fusanrium solani f. sp. cucurbitae). Both 3112PMR and H7B were designed to provide multiple disease-resistant background for the interspecific crosses; and Sugar Loaf is a winter squash that has a very fine flesh texture. The next two winter squash cultigens, Neck Pumpkin and Argonaut, have very strong vines, a large root system, and high heat and humidity tolerance, which were integrated into the interspecific-bridge lines for rootstocks. These two very long butternut varieties have a polymorphic curved neck problem, which was expected to be solved by the allelic introgression with an interspecific recombination. Within the last two maxima 


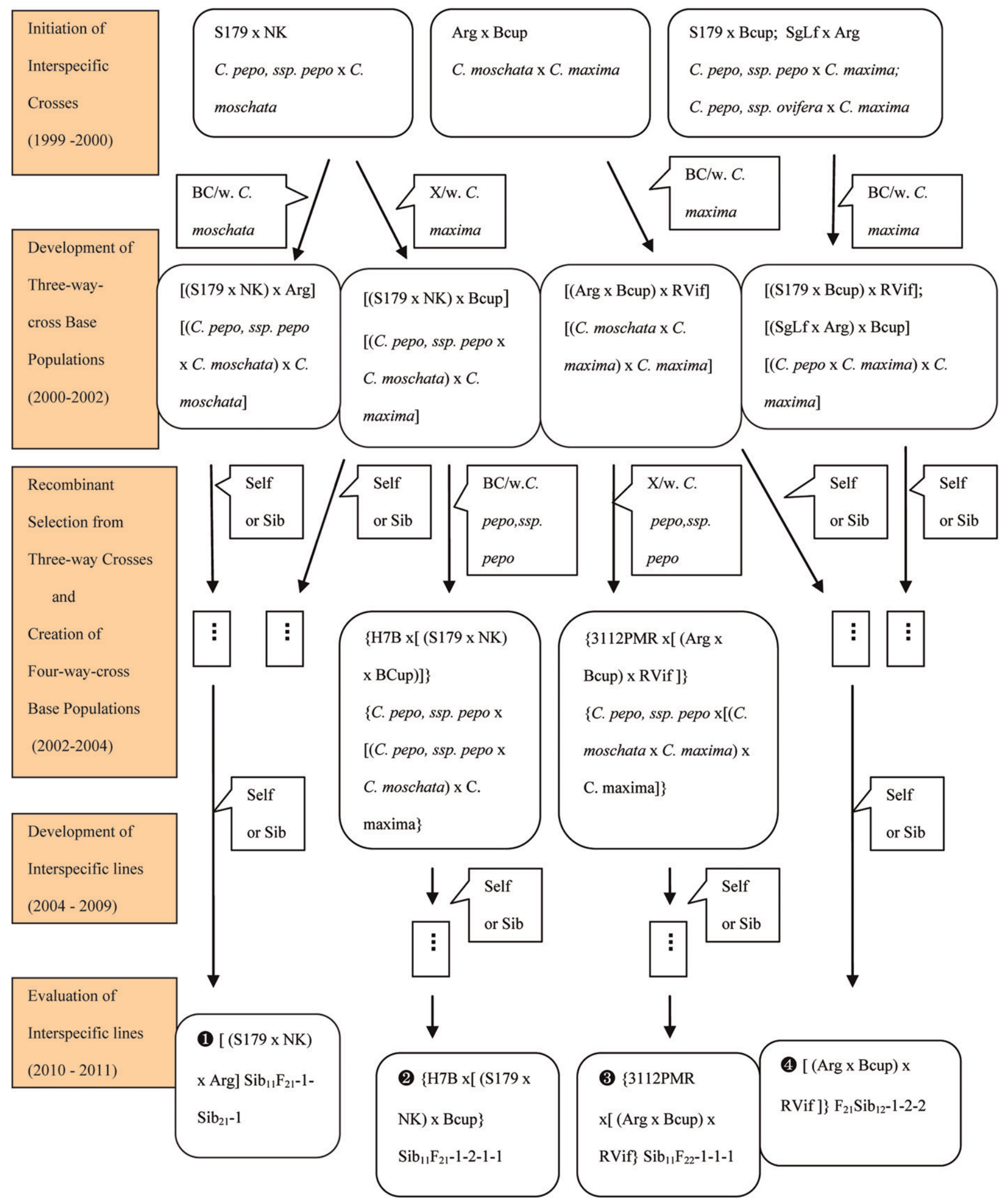

Fig. 1. Scheme of the development of interspecific-bridge lines. S179, 3112PMR, H7B, and SgLf (Sugar Loaf) are C. pepo squashes; Arg (Argonaut) and NK (Neck Pumpkin) are C. moschata winter squashes; Bcup (Buttercup) and RVif (Vif D'Etamps) are C. maxima pumpkins. "BC/w" and "X/w" mean "backcrossed with" and "crossed with," respectively. "Self" and "sib" represent "self-selection" and "sib-mating selection." $\mathbf{0}, \mathbf{2}, \mathbf{3}$, and $\mathbf{4}$ are newly developed inbred lines with stable crossing compatibility. " $\square$ " means continuous selection. 
pumpkins, Buttercup is a green fruit variety and Rouge Vif D'Etamps is a red fruit type that is not present in C. pepo and C. moschata. These two pumpkins also have a strong root system and full vine. Both of them have a flat, round fruit with a rich, sweet, and flavorful orange flesh that is fine-textured and dense in consistency. For the convenience of formalizing breeding pedigree, Sugar Loaf, Neck Pumpkin, Argonaut, Buttercup, and Rouge Vif D'Etamps are henceforth symbolized as "SgLf," "NK," "Arg," "Bcup," and "RVif" for all pedigrees.

The study was conducted with conventional breeding measures over a 12-year period from 1999 through 2011 (Fig. 1) at the research station of Hollar Seeds Company in Rocky Ford, CO. Multiple-parent populations and the advanced families or lines derived from them were largely created by interspecific crossing, backcrossing, sib-mating, and selfing for better fertility, self-compatibility, and a broader genetic background during the long-continued breeding process. To overcome crossing barriers including the time mismatch between pollen germination and pistillate receptivity, and individual differences in sexual incompatibility, repeated pollination and mixed-pollen pollination were adopted for the first two-way crosses and subsequent threeand four-way base populations. The pollination was repeatedly made by hand with bulked pollen from the plants of a male parent at $0700 \mathrm{HR}$ and $0900 \mathrm{HR}$ on the day of anthesis in Hollar's greenhouse in the fall and the spring seasons of 1999-2003. To surmount the male sterility and incompatibility of the interspecific $\mathrm{F}_{1}$ and its later generations, backcross and sib pollinations were used in the early generations, and pedigree and sib selections were alternatively implemented as the fertility and compatibility became higher in later generations. Four two-way crosses that were made first consisted of S179 $\times$ NK, SgLf $\times$ Arg, Arg $\times$ Bcup, and S179 $\times$ Bcup. After the seed of the four two-way crosses were obtained, six three-way and three four-way crosses were created as multiple-parent populations for the program to start the cycles of selection, which included: [(S179 $\times \mathrm{NK}) \times \mathrm{Arg}]$, $[(\mathrm{SgLf} \times \mathrm{Arg}) \times \mathrm{NK}],[(\mathrm{S} 179 \times \mathrm{NK}) \times \mathrm{Bcup}]$, $[(\operatorname{SgLf} \times$ Arg $) \times$ Bcup], [(Arg $\times$ Bcup $) \times$ RVif], $[(\mathrm{S} 179 \times$ Bcup $) \times$ Rvif $],\{$ H7B $\times[($ S179 $\times$ $\mathrm{NK}) \times \mathrm{Arg}]\},\{\mathrm{H} 7 \mathrm{~B} \times[(\mathrm{S} 179 \times \mathrm{NK}) \times \mathrm{Bcup}]\}$, and $\{3112 \mathrm{PMR} \times[(\mathrm{Arg} \times \mathrm{Bcup}) \times \mathrm{RVif}]\}$ (Table 1), where [....] and $\{. . .$.$\} represent the$ three- and four-parent base populations, respectively. Half-sib selection of male sterile plants and pedigree selection of fertile plants were conducted within the multiple-parent populations planted in the greenhouse during the spring or fall seasons of 2001 to 2003, and the same selection methods plus full-sib selection with open pollination were applied in an isolated field during the summers of the years and thereafter. The main systematic characteristics of the three species (Baggett, 1987) were taken as selection markers while selecting interspecific-derived plants or families. In accordance with the markers, plants with recombined traits were selected and

Table 1. Intermating effect among three cultivated species of Cucurbita on the seed setting of interspecific crosses

\begin{tabular}{|c|c|c|c|c|c|c|}
\hline \multirow[b]{2}{*}{ Cross $^{z}$} & \multirow[b]{2}{*}{ Year } & \multirow[b]{2}{*}{ No. of fruit } & \multicolumn{2}{|c|}{ No. of seeds } & \multirow[b]{2}{*}{$\operatorname{PFS}^{y}(\%)$} & \multirow[b]{2}{*}{$\mathrm{Y}^{\mathrm{x}}$} \\
\hline & & & Fertile & Rudimentary & & \\
\hline$\overline{\mathrm{S} 179 \times \mathrm{NK}}$ & 1999 & 15 & 12 & 2982 & 0.0267 & 0.1641 \\
\hline $\begin{array}{l}\text { C. pepo, ssp. pepo } \times \\
\text { C. moschata }\end{array}$ & & & & & & \\
\hline $\begin{array}{l}\mathrm{SgLf} \times \mathrm{Arg} \\
\text { C. pepo, ssp. ovifera } \times \\
\text { C. moschata }\end{array}$ & 1999 & 8 & 4 & 1441 & 0.0350 & 0.1882 \\
\hline $\begin{array}{l}\text { Arg } \times \mathrm{RVif} \\
\text { C. moschata } \times \\
\text { C. maxima }\end{array}$ & 1999 & 6 & 0 & 962 & 0.0000 & 0.0000 \\
\hline $\begin{array}{l}\mathrm{S} 179 \times \mathrm{RVif} \\
\text { C. pepo, ssp. pepo } \times \\
\text { C. maxima }\end{array}$ & 1999 & 7 & 0 & 1394 & 0.0000 & 0.0000 \\
\hline $\begin{array}{l}\mathrm{Arg} \times \text { Bcup } \\
\text { C. moschata } \times \\
\text { C. maxima }\end{array}$ & 2000 & 4 & 5 & 424 & 0.2925 & 0.5714 \\
\hline $\begin{array}{l}\mathrm{S} 179 \times \mathrm{Bcup} \\
\text { C. pepo, } \mathrm{ssp} . \text { pepo } \times \\
\text { C. maxima }\end{array}$ & 2000 & 9 & 6 & 1165 & 0.0567 & 0.2404 \\
\hline $\begin{array}{l}\text { Two-way cross mean } \\
(\mathrm{S} 179 \times \mathrm{NK}) \times \mathrm{Arg} \\
(\text { C. pepo, ssp. pepo } \times\end{array}$ & 2000 & 13 & 43 & 1560 & $\begin{array}{l}0.0685 \\
0.2062\end{array}$ & $\begin{array}{l}0.1940 \mathrm{~b} \\
0.4714\end{array}$ \\
\hline $\begin{array}{l}\text { C. moschata }) \times \\
\text { C. moschata }\end{array}$ & & & & & & \\
\hline $\begin{array}{l}(\mathrm{SgLf} \times \mathrm{Arg}) \times \mathrm{NK} \\
(\text { C. pepo, ssp. ovifera } \times \\
\quad \text { C. moschata }) \times \\
\text { C. moschata }\end{array}$ & 2000 & 12 & 51 & 1471 & 0.2792 & 0.5567 \\
\hline $\begin{array}{l}(\mathrm{S} 179 \times \mathrm{NK}) \times \mathrm{Bcup} \\
(\text { C. pepo, ssp. pepo } \times\end{array}$ & 2000 & 5 & 9 & 983 & 0.1820 & 0.4408 \\
\hline $\begin{array}{l}\text { C. moschata }) \times \text { C. maxima } \\
(\mathrm{SgLf} \times \mathrm{Arg}) \times \mathrm{Bcup} \\
(\text { C. pepo, } \mathrm{ssp} . \text { ovifera } \times \\
\text { C. moschata }) \times \text { C. maxima }\end{array}$ & 2000 & 11 & 13 & 1309 & 0.0891 & 0.3031 \\
\hline $\begin{array}{l}(\mathrm{Arg} \times \mathrm{Bcup}) \times \mathrm{RVif} \\
(\text { C. moschata } \times \text { C. maxima }) \times \\
\quad \text { C. maxima }\end{array}$ & 2001 & 3 & 16 & 551 & 0.9400 & 1.3233 \\
\hline $\begin{array}{l}(\mathrm{S} 179 \times \mathrm{Bcup}) \times \mathrm{Rvif} \\
(\text { C. pepo, } \mathrm{ssp} . \text { pepo } \times \\
\text { C. maxima }) \times \text { C. maxima }\end{array}$ & 2001 & 6 & 31 & 1202 & 0.4183 & 0.7033 \\
\hline Three-way cross mean & & & & & 0.3525 & $0.6331 \mathrm{a}$ \\
\hline $\begin{array}{l}\mathrm{H} 7 \mathrm{~B} \times[(\mathrm{S} 179 \times \mathrm{NK}) \times \mathrm{Arg}] \\
\text { C. pepo, ssp. pepo } \times[(\text { C. pepo, } \\
\text { ssp. pepo } \times \text { C. moschata }) \times \\
\text { C. moschata }]\end{array}$ & 2002 & 6 & 44 & 1260 & 0.5617 & 0.8473 \\
\hline $\begin{array}{l}\mathrm{H} 7 \mathrm{~B} \times[(\mathrm{S} 179 \times \mathrm{NK}) \times \mathrm{Bcup}] \\
\text { C. pepo, ssp. pepo } \times[(C . \text { pepo, } \\
\text { ssp. pepo } \times \text { C. moschata }) \times \\
\text { C. maxima }]\end{array}$ & 2002 & 7 & 53 & 1456 & 0.5014 & 0.7868 \\
\hline 3112PMR $[($ Arg $\times$ Bcup $) \times$ RVif $]$ & 2002 & 5 & 18 & 850 & 0.4140 & 0.6990 \\
\hline
\end{tabular}

C. pepo, ssp. pepo $\times$

$[($ C. moschata $\times$

C. maxima $) \times$ C. maxima $]$

Four-way cross mean

$0.4924 \quad 0.7777 \mathrm{a}$

${ }^{2} \mathrm{~S} 179$ (C. pepo, spp. pepo); NK = Neck Pumpkin (C. moschata); SgLf = Sugar Loaf (C. pepo, spp. ovifera); $\mathrm{Arg}=\operatorname{Argonaut}($ C. moschata $) ; \mathrm{RVif}=\operatorname{Rouge}$ Vif D'Etamps $($ C. maxima $) ; \mathrm{Bcup}=\operatorname{Buttercup}($ C. maxima $)$; H7B (C. pepo, spp. pepo); 3112PMR (C. pepo, spp. pepo).

${ }^{\mathrm{y}} \mathrm{Percentage}$ of fertile seeds per fruit (PFS), which is defined as: $\mathrm{PFS}=$ [no. of fertile seeds/(no. of fertile seeds + no. of rudimentary seeds) $] \times 100 \%$.

${ }^{x} \mathrm{Y}=$ Arcsine [square root (PFS)] which represents arcsine square root-transformed PFS for the variance stabilization of the proportional data. Mean separation within columns $(a, b)$ by least significant difference $(P=0.05)$. The transformed means bearing the same letters were not significantly different at the $5 \%$ level.

carried forward during the breeding procedure. Figure 2 shows the intermediate plant and fruit

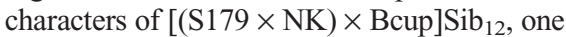
of those interspecific plants derived from the second individual in the first sib generation of the three-parent base population [(S179 $\times$ $\mathrm{NK}) \times$ Bcup]. This plant was selected based on the intermediate vine of S179 $\times \mathrm{NK}$, intermediate fruit of $\mathrm{S} 179 \times \mathrm{Bcup}$, and the color and peduncle of S179 in the summer of 2001. No attempt was made to determine the genetic mechanism of genes or traits involved, and no disease-screening was conducted to avoid losing limited interspecific seeds in the study. However, the fertility, cross-, and self-compatibility of advanced families or lines were considered the main acquired characteristics for selection with the integration of other important traits as 


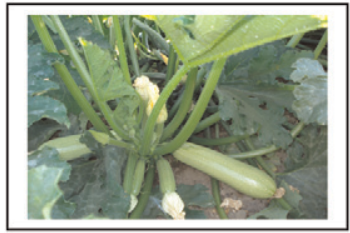

Picture1. S179

(C. pepo, ssp. pepo)

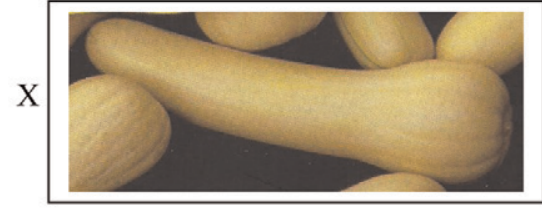

Picture 2. Neck Pumpkin

(C. moschata)

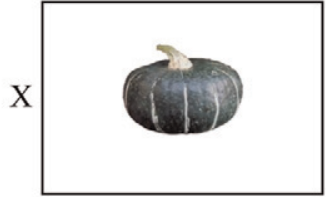

Picture 3. Buttercup

(C. maxima).

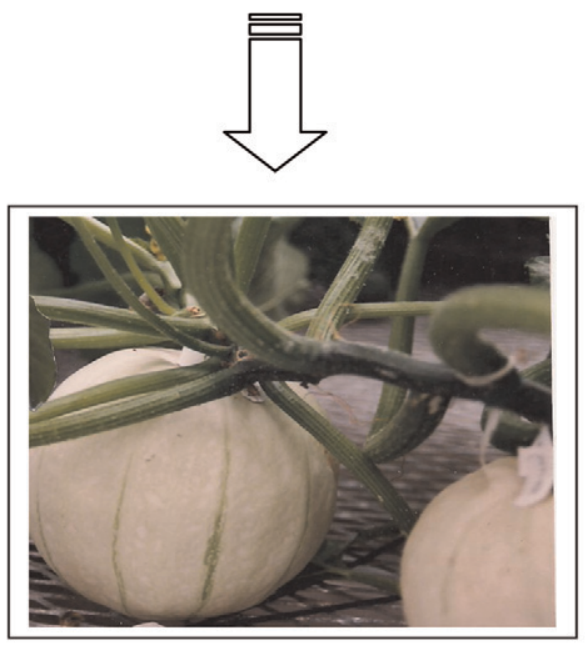

Picture 4. $[(\mathrm{S} 179 \mathrm{xNK}) \mathrm{xBcup}] \mathrm{Sib}_{12}$

\section{[(C. pepo, ssp. pepo x C. moschata $) \times$ C. maxima $]$}

Fig. 2. Recombination of S179 (C. pepo, ssp. pepo), Neck Pumpkin (C. moschata) and Buttercup (C. maxima), and an interspecific plant [(S179 $\times$ NK) $\times$ Bcup] $\mathrm{Sib}_{12}$ derived from the second plant $\left(\mathrm{Sib}_{\mathrm{i} 2}\right)$ in the first sib generation $\left(\mathrm{Sib}_{1 \mathrm{j}}\right)$ of the base population $[(\mathrm{S} 179 \times \mathrm{NK}) \times \mathrm{Bcup}]$.

mentioned previously. The crossing-, selfing-, and sib-mating compatibility were measured by the PFS, which is defined as: PFS = [no. of fertile seeds/(no. of fertile seeds + no. of rudimentary seeds) $] \times 100 \%$, in which the rudimentary seed is an empty seedcoat or an undeveloped small seedcoat rudiment. To stabilize the variance in the proportional data and get a better understanding on the breeding progress, PFS values were transformed by arcsine square root during the data analysis and mean separation.

By the end of 2009, nine advanced interspecific lines out of 31 became stable in all acquired traits. Considering the availability of seeds, only four interspecific-bridge lines in the nine were picked as female parents to evaluate their crossing compatibility in the spring of 2010 and 2011 (Fig. 1). The four interspecific inbred lines were $[(\mathrm{S} 179 \times \mathrm{NK}) \times$ Arg] $\mathrm{Sib}_{11} \mathrm{~F}_{21}-1-\mathrm{Sib}_{21}-1$, [(Arg $\times$ Bcup $\left.) \times \mathrm{RVif}\right]$ $\mathrm{F}_{21} \mathrm{Sib}_{12}-1-2-2,\{\mathrm{H} 7 \mathrm{~B} \times[(\mathrm{S} 179 \times \mathrm{NK}) \times \mathrm{Bcup}]\}$ $\mathrm{Sib}_{11} \mathrm{~F}_{21}-1-2-1-1$, and $\{3112 \mathrm{PMR} \times[(\mathrm{Arg} \times$ Bcup) $\times$ RVif] $\} \mathrm{Sib}_{11} \mathrm{~F}_{22}-1-1-1$, in which $\mathrm{Sib}_{11}$, $\mathrm{Sib}_{12} \ldots . . \mathrm{Sib}_{\mathrm{ij}} ; \mathrm{Sib}_{21}, \mathrm{Sib}_{22} \ldots . . \mathrm{Sib}_{\mathrm{ij}}$ and $\mathrm{F}_{21}, \mathrm{~F}_{22}$.. .. $\mathrm{F}_{\mathrm{ij}}$ mean sib and self populations, respectively, where $i$ refers to $i^{\text {th }}$ generation and $j$ represents $j^{\text {th }}$ plant or family selected (Figs. 1 and 2). Twelve interspecific crosses were made by crossing interspecific inbred lines with three males-Longzuc163 (C. pepo), Waltham (C. moschata), and Orange Banana (C. maxima) in the greenhouse. At the same time, three intracrosses were made for comparisons, which consisted of Black Beauty (C. pepo) $\times$ LnogZuc163 (C. pepo), Neck Pumpkin (C. moschata $) \times$ Waltham $(C$. moschata $)$, and Rouge Vif D'Etamps $(C$. maxima $) \times$ Orange Banana (C. maxima). Mean separations of transformed PFS values were used to evaluate the compatible differences among the crosses and parents.

\section{Results and Discussion}

Fruit-set rate from the four two-way crosses of the interspecific hybridizations made at the very beginning was very low (Table 1 ). There were only a few fruit resulting from a hundred pollinations in each cross that could reach the mature stage without abortion. Of the mature fruit, most were parthenocarpic with empty seedcoats or seedcoat rudiments. Results (Table 1) indicate that the plant and population compatibility significantly increased ( $\mathrm{F}_{0.05}$ ) when a backcross with a recurrent parent in the same species or a three-way cross with a parent in the different species was made, in which PFS among the two-, three-, and fourway crosses changed from $0 \%$ to $0.2925 \%$, $0.0891 \%$ to $0.4183 \%$, and $0.4140 \%$ to $0.5617 \%$, respectively. The difference of PFS levels, although non-significant, between three- and four-way crosses demonstrates some effect of one more intermating because there was a trend for the higher level of PFS in four-way crosses. Based on the results of the interspecific hybridization, breeders should start to make selections from a three-way cross base population for a high rate of viable seeds and timing efficiency regardless of whether C. moschata, C. maxima, C. pepo, spp. pepo, or $C$. pepo, spp. ovifera parents are used.

Most of the plants from the two-, three-, and four-way interspecific crosses were partially or completely male sterile with three forms of sterility found: 1) a pollen-aborted male sterility in which male flowers had shrunken anthers with a partial or complete failure of pollen production with pollen fertility varying from $0 \%$ to $35 \%$; 2 ) an aborted male flower that was characterized by the staminate blossoms, which had only rudimentary anthers with no pollen present; and 3 ) a closed flower type in which both or either staminate and pistillate flowers failed to open at maturity with closed staminate sterile flowers 
most often seen. Half-sib pollination for the male sterile plants and self-pollination for the partially and fully fertile plants seemed to be the most effective ways to create initial populations with tremendous genetic variability from the three- and four-way crosses for selection.

The early generations that were created from all the multiple-parent populations by sib- or self-pollinations segregated enormously in all traits including plant and fruit types, disease resistance, sex expression, fertility, and self- and sib-compatibility. Regardless of the genetic diversity, the PFS gain (Table 2) of $\mathrm{Sib}_{1 \mathrm{j}} \mathrm{F}_{2 \mathrm{j}}, \mathrm{F}_{2 \mathrm{j}} \mathrm{Sib}_{1 \mathrm{j}}$, or $\mathrm{F}_{2}-1$ families selected from the populations $\mathrm{Sib}_{1 \mathrm{j}}$ and $\mathrm{F}_{2 \mathrm{j}}$ made the new PFS level significantly higher $\left(\mathrm{F}_{0.05}\right)$ in one generation's progress based on the arsine square root-transformed PFS test. From the effects of mating systems, the PFS resulted from sib mating and selfing were not evidently different from each other at the same generation. When selection continued, the PFS of subsequent lines from the early generations could be expected to reach an intraspecific selfing level (or a normal level).

As the breeding process was proceeding to the third generation from the base populations, the pedigree selection was mostly used to stabilize acquired characteristics and conduct the further improvement of PFS to realize our breeding objectives. During the development of the interspecific families and lines, it was found that the frequencies of some characteristics were skewed in favor of C. moschata and C. maxima in all populations, especially the fruit and plant type. All of the families and lines obtained had a vine and a winter squash or pumpkin fruit no matter how they varied in length, shape, or size. Although the bush gene in C. pepo and C. maxima was reported to be dominant to the vine gene during early growth and incompletely dominant during later growth (Denna and Munger, 1963; Shifriss, 1947; Zack and Loy, 1979), there were no zucchini-bush-type plants to be found in any recombined early populations or advanced families and lines in this study. The skewed segregations, which resulted from linkage to major pollenexpressed compatibility loci, were found in the backcross populations of interspecific crosses in Solanaceae family (Chetelat and DeVerna, 1991). As to whether the genetic expression of the bush trait between or among the species in the Cucurbita genus associates with incompatibility loci or other causes, more research is required.

From the results in Table 3, it is clear that in all 12 crosses derived from the four interspecific lines, five of them had the same PFS level as the three intraspecific crosses. When considering the effect of parents on compatibility, three of the four interspecific females $[(\mathrm{S} 179 \times \mathrm{NK}) \times \mathrm{Arg}] \mathrm{Sib}_{11} \mathrm{~F}_{21}-1-$ $\mathrm{Sib}_{21}-1,\{\mathrm{H} 7 \mathrm{~B} \times[(\mathrm{S} 179 \times \mathrm{NK}) \times \mathrm{Bcup}]\}$ $\mathrm{Sib}_{11} \mathrm{~F}_{21}-1-2-1-1$, and $[(\operatorname{Arg} \times$ Bcup $) \times \mathrm{RVif}]$ $\mathrm{F}_{21} \mathrm{Sib}_{12}-1-2-2$, produced seven crosses with significantly different PFS values $(P=0.05)$ compared with that of the intraspecific females. The female $\{3112 \mathrm{PMR} \times[(\mathrm{Arg} \times \mathrm{Bcup})$
Table 2. Percentage of fertile seeds per fruit (PFS) of early generation selections derived from interspecific multiple-parent populations

\begin{tabular}{|c|c|c|c|c|}
\hline \multirow[b]{2}{*}{ Pedigree $^{z}$} & \multicolumn{2}{|c|}{ No. of seeds } & \multirow[b]{2}{*}{ PFS (\%) } & \multirow[b]{2}{*}{$\mathrm{Y}^{\mathrm{y}}$} \\
\hline & $\overline{\text { Fertile }}$ & $\overline{\text { Rudimentary }}$ & & \\
\hline $\begin{array}{l}{[(\mathrm{S} 179 \times \mathrm{NK}) \times \mathrm{Arg}] \mathrm{Sib}_{11}} \\
{[(\text { C. pepo }, \mathrm{ssp} . \text { pepo } \times \text { C. moschata }) \times \text { C. moschata }]}\end{array}$ & 55 & 296 & 15.67 & 0.4070 \\
\hline $\begin{array}{l}{[(\mathrm{S} 179 \times \mathrm{NK}) \times \mathrm{Arg}] \mathrm{Sib}_{12}} \\
{[(\text { C. pepo }, \mathrm{ssp} . \text { pepo } \times \text { C. moschata }) \times \text { C. moschata }]}\end{array}$ & 77 & 314 & 19.69 & 0.4598 \\
\hline 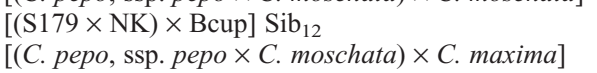 & 41 & 302 & 11.95 & 0.3530 \\
\hline $\begin{array}{l}{[(\mathrm{SgLf} \times \mathrm{Arg}) \times \mathrm{Bcup}] \mathrm{Sib}_{11}} \\
{[(\text { C. pepo }, \text { ssp. ovifera } \times \text { C. moschata }) \times \text {. maxima }]}\end{array}$ & 89 & 240 & 27.05 & 0.5470 \\
\hline $\begin{array}{l}{\left[(\mathrm{Arg} \times \mathrm{Bcup}) \times \mathrm{RVif}^{\mathrm{S}}\right] \mathrm{Sib}_{11}} \\
{[(\text { C. moschata } \times \text { C. maxima }) \times C . \text { maxima }]}\end{array}$ & 92 & 191 & 32.51 & 0.6067 \\
\hline $\begin{array}{l}{[(\mathrm{S} 179 \times \mathrm{Bcup}) \times \mathrm{Rvif}] \mathrm{Sib}_{11}} \\
{[(\text { C. pepo }, \text { ssp. pepo } \times \text { C. maxima }) \times \text { C. maxima }]}\end{array}$ & 116 & 202 & 36.48 & 0.6485 \\
\hline $\begin{array}{l}\{\mathrm{H} 7 \mathrm{~B} \times[(\mathrm{S} 179 \times \mathrm{NK}) \times \mathrm{Bcup}]\} \mathrm{Sib}_{12} \\
\{\text { C. pepo, ssp. pepo } \times[(\text { C. pepo, ssp. pepo } \times \\
\quad \text { C. moschata }) \times \text { C. maxima }]\}\end{array}$ & 78 & 250 & 23.78 & 0.5094 \\
\hline$\{3112 \mathrm{PMR} \times[(\mathrm{Arg} \times \mathrm{Bcup}) \times \mathrm{RVif}]\} \mathrm{Sib}_{12}$ & 111 & 195 & 36.28 & 0.6464 \\
\hline
\end{tabular}

$\{$ C. pepo, ssp pepo $\times[($ C moschata $\times$

C. maxima $) \times C$. maxima $]\}$

$\mathrm{Sib}_{1 \mathrm{j}}$ mean

$[(\mathrm{S} 179 \times \mathrm{NK}) \times \mathrm{Arg}] \mathrm{F}_{21}$

$[(C$. pepo, ssp. pepo $\times$ C. moschata $) \times C$. moschata $]$

$[(\mathrm{S} 179 \times \mathrm{NK}) \times \mathrm{Bcup}] \mathrm{F}_{21}$

$[(C$. pepo, ssp. pepo $\times$ C. moschata $) \times C$. maxima $]$

$\left[(\operatorname{SgLf} \times \mathrm{Arg}) \times \mathrm{Bcup} \mathrm{F}_{21}\right.$

$[($ C. pepo, ssp. ovifera $\times$ C. moschata $) \times C$. maxima $]$

$[($ Arg $\times$ Bcup $) \times$ RVif $] \mathrm{F}_{22}$

$[(C$. moschata $\times$ C. maxima $) \times C$. maxima $]$

$[(\mathrm{S} 179 \times$ Bcup $) \times \mathrm{Rvif}] \mathrm{F}_{21}$

$[(C$. pepo, ssp. pepo $\times$ C. maxima $) \times$ C. maxima $]$

$\{\mathrm{H} 7 \mathrm{~B} \times[(\mathrm{S} 179 \times \mathrm{NK}) \times \mathrm{Bcup}]\} \mathrm{F}_{21}$

$\{$ C. pepo, ssp. pepo $\times[($ C. pepo, ssp. pepo $\times$

C. moschata $) \times C$. maxima $]\}$

$\{3112 \mathrm{PMR} \times[(\mathrm{Arg} \times \mathrm{Bcup}) \times \mathrm{RVif}]\} \mathrm{F}_{22}$

$\{$ C. pepo, ssp. pepo $\times[($ C. moschata $\times$

C. maxima $) \times$ C. maxima $]\}$

$\mathrm{F}_{2 \mathrm{j}}$ mean

$[(\mathrm{S} 179 \times \mathrm{NK}) \times \mathrm{Arg}] \mathrm{Sib}_{11} \mathrm{~F}_{21}$

$[($ C. pepo, ssp. pepo $\times$ C. moschata $) \times$ C. moschata $]$

$[(\mathrm{S} 179 \times \mathrm{NK}) \times \mathrm{Bcup}] \mathrm{Sib}_{12} \mathrm{~F}_{21}$

$[(C$. pepo, ssp. pepo $\times$ C. moschata $) \times C$. maxima $]$

$[(\operatorname{SgLf} \times \operatorname{Arg}) \times$ Bcup $] \mathrm{Sib}_{11} \mathrm{~F}_{21}$

$[(C$. pepo, ssp. ovifera $\times$ C. moschata $) \times$ C. maxima $]$

$[($ Arg $\times$ Bcup $) \times$ RVif $] \mathrm{Sib}_{11} \mathrm{~F}_{21}$

[(C. moschata $\times$ C. maxima $) \times$ C. maxima $]$

$\{\mathrm{H} 7 \mathrm{~B} \times[(\mathrm{S} 179 \times \mathrm{NK}) \times \mathrm{Arg}]\} \mathrm{Sib}_{11} \mathrm{~F}_{22}$

$\{$ C. pepo, ssp. pepo $\times[($ C.pepo, ssp. pepo $\times$

C. moschata $\times$ C. moschata $]\}$

$\{\mathrm{H} 7 \mathrm{~B} \times[(\mathrm{S} 179 \times \mathrm{NK}) \times \mathrm{Arg}]\} \mathrm{Sib}_{12} \mathrm{~F}_{21}$

$\{$ C. pepo, ssp. pepo $\times[($ C. pepo, ssp. pepo $\times$

C. moschata $\times$ C. moschata $]\}$

$\{\mathrm{H} 7 \mathrm{~B} \times[(\mathrm{S} 179 \times \mathrm{NK}) \times \mathrm{Bcup}]\} \mathrm{Sib}_{11} \mathrm{~F}_{21}$

$\{C$. pepo, ssp. pepo $\times[(C$. pepo, ssp. pepo $\times$

C. moschata $) \times$ C. maxima $]\}$

$\{3112 \mathrm{PMR} \times[$ (Arg $\times$ Bcup $) \times \mathrm{RVif}]\} \mathrm{Sib}_{11} \mathrm{~F}_{22}$

$\{$ C. pepo, ssp. pepo $\times[($ C. moschata $\times$

C. maxima $) \times C$. maxima $]\}$

$[(\mathrm{SgLf} \times \mathrm{Arg}) \times \mathrm{NK}] \mathrm{F}_{21} \mathrm{Sib}_{11}$

$0.5222 \mathrm{c}$

$[(C$. pepo, ssp. ovifera $\times$ C. moschata $) \times$

C. moschata]

$[($ Arg $\times$ Bcup $) \times \mathrm{RVif}] \mathrm{F}_{21} \mathrm{Sib}_{12}$

$[(C$. moschata $\times$ C. maxima $) \times C$. maxima $]$

$\{\mathrm{H} 7 \mathrm{~B} \times[(\mathrm{S} 179 \times \mathrm{NK}) \times \mathrm{Bcup}]\} \mathrm{F}_{21} \mathrm{Sib}_{11}$

$\{$ C. pepo, ssp. pepo $\times[(C$. pepo, ssp. pepo $\times$

C. moschata $\times$ C. maxima $]\}$

$\{\mathrm{H} 7 \mathrm{~B} \times[(\mathrm{S} 179 \times \mathrm{NK}) \times \mathrm{Bcup}]\} \mathrm{F}_{22} \mathrm{Sib}_{11}$

$\{$ C. pepo, ssp. pepo $\times[($ C. pepo, ssp. pepo $\times$

C. moschata $\times$ C. maxima $]$

$\mathrm{Sib}_{1 \mathrm{j}} \mathrm{F}_{2 \mathrm{j}}$ and $\mathrm{F}_{2 \mathrm{j}} \mathrm{Sib}_{1 \mathrm{j}}$ mean

$\left[(\mathrm{S} 179 \times \mathrm{NK}) \times \mathrm{Arg} \mathrm{F}_{21}-1\right.$

$[(C$. pepo, ssp. pepo $\times$ C. moschata $) \times$ C. moschata $]$

$\left[(\mathrm{S} 179 \times \mathrm{NK}) \times \mathrm{Bcup} \mathrm{F}_{22}-1\right.$

$[(C$. pepo, ssp. pepo $\times$ C. moschata $) \times C$. maxima $]$

$$
286
$$

0.2552

$$
261
$$

0.3256

0.3851

$\begin{array}{lll}219 & 33.44 & 0.3344\end{array}$


Table 2. (Continued) Percentage of fertile seeds per fruit (PFS) of early generation selections derived from interspecific multiple-parent populations

\begin{tabular}{|c|c|c|c|c|}
\hline \multirow[b]{2}{*}{ Pedigree $^{z}$} & \multicolumn{2}{|c|}{ No. of seeds } & \multirow[b]{2}{*}{ PFS (\%) } & \multirow[b]{2}{*}{$\mathrm{Y}^{\mathrm{y}}$} \\
\hline & Fertile & Rudimentary & & \\
\hline$\{\mathrm{H} 7 \mathrm{~B} \times[(\mathrm{S} 179 \times \mathrm{NK}) \times \mathrm{Arg}]\} \mathrm{F}_{21^{-1}}$ & 185 & 197 & 48.43 & 0.4843 \\
\hline $\begin{array}{l}\{\text { C. pepo, ssp. pepo } \times[(C \text {. pepo, ssp. pepo } \times \\
\text { C. moschata }) \times \text { C. moschata }]\}\end{array}$ & & & & \\
\hline $\begin{array}{l}\{\mathrm{H} 7 \mathrm{~B} \times[(\mathrm{S} 179 \times \mathrm{NK}) \times \mathrm{Arg}]\} \mathrm{F}_{22}-1 \\
\{\text { C. pepo, ssp. pepo } \times[(\text { C. pepo, } \text { ssp. pepo } \times \\
\quad \text { C. moschata }) \times \text { C. moschata }]\}\end{array}$ & 161 & 250 & 39.17 & 0.3917 \\
\hline $\begin{array}{l}\{3112 \mathrm{PMR} \times[(\mathrm{Arg} \times \mathrm{Bcup}) \times \mathrm{RVif}]\} \mathrm{F}_{21}-1 \\
\{\text { C. pepo, ssp. pepo } \times[(\text { C. moschata } \times \\
\quad \text { C. maxima }) \times \text { C. maxima }]\}\end{array}$ & 140 & 261 & 34.91 & 0.3491 \\
\hline$F_{2 j}-1$ mean & & & 40.66 & 0.6907 \\
\hline $\mathrm{S} 179$ (С. реро, spp. реро) & 236 & 123 & 65.74 & 0.6574 \\
\hline Neck Pumpkin (C. moschata) & 242 & 118 & 67.22 & 0.6722 \\
\hline Rouge Vif D'Etamps (C. maxima) & 305 & 195 & 61.00 & 0.6100 \\
\hline Intra-sp selfing mean & & & 64.65 & 0.9343 \\
\hline
\end{tabular}

${ }^{{ }^{2}}$ S179 (C. pepo, spp. pepo $) ; \mathrm{NK}=$ Neck Pumpkin (C. moschata $) ; \operatorname{SgLf}=$ Sugar Loaf $($ C. pepo, spp. ovifera $) ;$ $\operatorname{Arg}=\operatorname{Argonaut}($ C. moschata $) ; \mathrm{RVif}=\operatorname{Rouge}$ Vif D'Etamps $($ C. maxima $) ; \operatorname{Bcup}=\operatorname{Buttercup}($ C. maxima $)$ H7B (C. pepo, spp. pepo), 3112PMR (C. pepo, spp. pepo). [....] and \{....\} represent the three- and fourparent base populations of interspecific crosses, respectively.

$\mathrm{Sib}_{11}, \mathrm{Sib}_{12} \ldots . . \mathrm{Sib}_{\mathrm{ij}} ; \mathrm{Sib}_{21}, \mathrm{Sib}_{22} \ldots . . \mathrm{Sib}_{\mathrm{ij}} ; \mathrm{F}_{21}, \mathrm{~F}_{22} \ldots . \mathrm{F}_{\mathrm{ij}}$, where $\mathrm{i}=\mathrm{i}^{\text {th }}$ generation and $\mathrm{j}=\mathrm{j}^{\text {th }}$ plant selected in the interspecific families. Intrasp means "within a species."

${ }^{\mathrm{y}}$ Mean separation within columns $(\mathrm{a}, \mathrm{b}, \mathrm{c})$ by least significant difference $(P=0.05)$ derived from arcsine square root-transformed PFS data. The transformed means bearing the same letters were not significantly different at the $5 \%$ level.

Table 3. Test of crossing compatibility between advanced interspecific-bridge lines and the cultigens of Cucurbita pepo, C. moschata, and C. maxima.

\begin{tabular}{|c|c|c|c|c|}
\hline \multicolumn{2}{|c|}{ Cross } & \multirow[b]{2}{*}{ PFS (\%) } & \multirow[b]{2}{*}{$Y^{y}$} & \multirow[b]{2}{*}{$Z^{x}$} \\
\hline Female $^{z}$ & Male & & & \\
\hline $\begin{array}{c}{[(\mathrm{S} 179 \times \mathrm{NK}) \times \mathrm{Arg}]} \\
\mathrm{Sib}_{11} \mathrm{~F}_{21}-1-\mathrm{Sib}_{21}-1\end{array}$ & $\begin{array}{l}\text { LongZuc163 } \\
\quad \text { (C. pepo, ssp. pepo) }\end{array}$ & 59.97 & $0.8857 \mathrm{bc}$ & \\
\hline $\begin{array}{l}{[(C . \text { pepo }, \text { ssp. pepo } \times} \\
\quad \text { C. moschata }) \times \text { C. moschata }]\end{array}$ & $\begin{array}{l}\text { Waltham } \\
\quad \text { (C. moschata) }\end{array}$ & 59.38 & $0.8799 \mathrm{bc}$ & $0.8828 \mathrm{a}$ \\
\hline $\begin{array}{l}{[(\mathrm{S} 179 \times \mathrm{NK}) \times \mathrm{Arg}]} \\
\mathrm{Sib}_{11} \mathrm{~F}_{21^{-1}-\mathrm{Sib}_{21}-1}\end{array}$ & $\begin{array}{l}\text { Orange Banana } \\
\quad(\text { C. maxima })\end{array}$ & 22.16 & $0.4900 \mathrm{~d}$ & \\
\hline $\begin{array}{l}{[(\text { C. pepo }, \text { ssp. pepo } \times} \\
\quad \text { C. moschata }) \times \text { C. moschata }]\end{array}$ & & & & \\
\hline $\begin{array}{l}{[(\mathrm{Arg} \times \mathrm{Bcup}) \times \mathrm{RVif}]} \\
\mathrm{F}_{21} \mathrm{Sib}_{12}-1-2-2\end{array}$ & $\begin{array}{l}\text { LongZuc163 } \\
\quad \text { (C. pepo, ssp. pepo) }\end{array}$ & 18.82 & $0.4485 \mathrm{~d}$ & \\
\hline
\end{tabular}

$[($ C. moschata $\times$ C. maxima $) \times$

C. maxima]

[(Arg $\times$ Bcup $) \times$ RVif $]$

$\mathrm{F}_{21} \mathrm{Sib}_{12}-1-2-2$

$[($ C. moschata $\times$ C. maxima $) \times$

C. maxima]

$\{\mathrm{H} 7 \mathrm{~B} \times[(\mathrm{S} 179 \times \mathrm{NK}) \times \mathrm{Bcup}]\}$

$\mathrm{Sib}_{11} \mathrm{~F}_{21}-1-2-1-1$

$\{C$. pepo, ssp. pepo $\times$

$[(C$. pepo, ssp. pepo $\times$

C. moschata $) \times$ C. maxima $]\}$

$\{3112 \mathrm{PMR} \times[(\operatorname{Arg} \times$ Bcup $) \times$

RVif]\} $\mathrm{Sib}_{11} \mathrm{~F}_{22}-1-1-1$

(C. pepo, ssp. pepo)

$0.4693 \mathrm{~b}$

Waltham (C. moschata)

$63.60 \quad 0.9231 \mathrm{ab}$

Orange Banana (C. maxima)

$62.24 \quad 0.9091 \mathrm{ab}$

LongZuc163

(C. pepo, ssp. pepo)

Waltham (C. moschata)

$66.96 \quad 0.9585 a$

0.9161 a

$62.80 \quad 0.9148 \mathrm{abc}$

Orange Banana (C. maxima)

LongZuc163

(C. pepo, ssp. pepo)

$\{$ C. pepo, ssp. pepo $\times[($ C. moschata $\times$ Waltham $($ C. moschata $)$

C. maxima $) \times C$. maxima $]\}$

Black Beauty (C. pepo, ssp. pepo)

Orange Banana (C. maxima) LongZuc163

(C. pepo, ssp. pepo)

Neck Pumpkin (C. moschata)

Waltham (C. moschata)
$53.94 \quad 0.8249 \mathrm{c}$

$60.91 \quad 0.8954 \mathrm{ab}$

$0.8994 \mathrm{a}$

$62.09 \quad 0.9076 \mathrm{ab}$

$63.54 \quad 0.9225 \mathrm{ab}$

$63.49 \quad 0.9223 \mathrm{ab}$

$62.02 \quad 0.9068 \mathrm{ab}$ $\begin{array}{lllll}\text { Rouge Vif D'Etamps (C. maxima) } & \text { Orange Banana (C. maxima) } & 64.22 & 0.9295 \mathrm{ab} & 0.9136 \mathrm{a}\end{array}$

$\begin{array}{lllll}\text { Rouge Vif D'Etamps (C. maxima) } & \text { Orange Banana (C. maxima) } & 64.22 & 0.9295 \mathrm{ab} & 0.9136 \mathrm{a}\end{array}$

${ }^{2} \mathrm{~S} 179$ (C. pepo, spp. pepo); NK = Neck Pumpkin (C. moschata); Arg = Argonaut (C. moschata); RVif $=$ Rouge Vif D’Etamps (C. maxima); Bcup = Buttercup (C. maxima); H7B (C. pepo, spp. pepo), 3112PMR (C. pepo, spp. pepo); [....] and $\{\ldots .$.$\} represent the three- and four-parent base populations of interspecific$ crosses, respectively.

${ }^{\mathrm{y}}$ Mean separation within columns by least significant difference $(P=0.05)$ derived from arcsine square root-transformed PFS data. The transformed means bearing the same letters were not significantly different at the $5 \%$ level.

${ }^{x}$ Mean separation within columns $(\mathrm{a}, \mathrm{b})$ by least significant difference $(P=0.05)$ derived from arcsine square root-transformed data. The means with "a" came from crosses that a cultigen was present in the female line pedigree as the same species of the male parents; the mean with "b" was derived from the crosses that male lines were third species, which were not present the female lines. The transformed means bearing the same letters were not significantly different at the $5 \%$ level.

$\mathrm{PFS}=$ percentage of fertile seeds per fruit. $\times$ RVif] $\} \mathrm{Sib}_{11} \mathrm{~F}_{22}-1-1-1$ generated crosses with the same PFS level as that of the three intraspecific females. Despite the PFS variability of each individual cross, the PFS means from 15 crosses in two growing seasons showed that there was a trend among all crosses for the interspecific-bridge female lines to bring about a normal or near-normal seed setting when the male lines were in the same species as the cultigens that presented in the threeand four-parent base populations of the female lines. The interspecific-bridge female lines derived from a two-species population had significantly lower fertile seed set (PFS $=$ $22.16 \%, 18.82 \% ; Z=0.4693$ ) when crossed with the third species as compared with the intraspecific females and the interspecificbridge lines carrying the cultigens, which were in the same species as the male parent, but the crossing compatibility was inclined to be considerably increased by contrasting with the initial interspecific crosses (S179 $\times$ $\mathrm{NK}) \times$ Bcup and $(\operatorname{SgLf} \times \operatorname{Arg}) \times$ Bcup during the creation of base populations (PFS = $0.1820 \%, 0.0891 \%$ ) (Table 1$)$. In other words, the interspecific inbred lines derived from the three-species base populations had a broader compatibility than the lines resulted from the two-species base populations, although successive selection pronouncedly increased the compatibility for all the lines.

Based on the results of this study, it can be concluded that interspecific inbred lines with a normal sexual compatibility could be successfully developed by varietal recombination among species and successive selection toward increasing compatibility of interspecific crosses and the successively derived generations. Unlike previously generated or used interspecific bridge lines discussed in the introduction, the newly bred interspecificbridge lines among Cucurbita pepo, C. moschata, and $C$. maxima in the Cucurbita genus could not only overcome the crossing barriers of interspecific hybridization, but also eliminate the sexual obstacles of the subsequent generations. This important breakthrough has created a powerful platform for breeders to transfer favorable characteristics among the species freely without the introgression of unfavorable traits from a wild species during the breeding process. With these compatible interspecific inbred lines, breeders could greatly reduce the negative effect of natural selection caused by incompatibility and more effectively transfer important traits to targeted lines during an interspecific breeding process. Because the interspecific inbred lines are not different in compatibility from intraspecific inbred lines, they could be able to sexually reproduce themselves normally. As recombined results of elite inbred lines or varieties among the three species, these interspecific lines could be used to make dual-purpose summer squashes with immature fruit harvested as zucchini and the mature fruit as winter squash with the flesh texture of maxima or moschata fruit. They also could be used to convert a moschata or maxima vine to a pepo bush for the convenience of seed production using the male flower chemical 
debudding or vice versa for grafting rootstocks integrated with soil-disease resistance. By means of the genetic bridges, significant expansion of valuable and unique types or varieties can take place through trait introgression among the species in the genus.

\section{Literature Cited}

Baggett, J. R. 1979. Attempts to vross Cucurbita moschata (Duch.) Poir. 'Butternut' and C. pepo L. 'Delicata'. Cucurbit Genetics Cooperative Report 2:32-34 (article 19).

Baggett, J.R. 1987. Systematic fruits and vegetables (textbook). p. 108-114

Bemis, W.P. 1973. Interspecific aneuploidy in Cucurbita. Genet. Res. 21:221-228.

Blanca, J., J. Canizares, C. Roig, P. Ziarsolo, F. Nuez, and B. Pico. 2011. Transcriptome characterization and high throughput SSRs and SNPs discovery in Cucurbita pepo (Cucurbitaceae). BMC Genomics. <http://www.highbeam. com/doc/1G1-250836534.html>.

Castetter, E.F. 1930. Species crosses in the genus Cucurbita. Amer. J. Bot. 17:41-57.

Chekalina, I.N. 1974. The efficiency of some methods of overcoming incompatibility on crossing different species of cucurbits. Sel'skokhozyaistuennaya Biologiya 8:670-672.

Chen, J.P., X.H. Ge, X.C. Yao, Y.H. Feng, and Z.Y. Li. 2011. Synthesis and characterization of interspecific trigenomic hybrids and allohexaploids between three cultivated Brassica allotetroploids and wild species Brassica fruticulosa. Afr. J. Biotechnol. 10:12171-12176.

Cheng, Y.G., B.K. Zhang, E.H. Zhang, and Z.L. Zhao. 2002. Germplasm innovation by interspecific crosses in pumpkin. Cucurbit Genetics Cooperative Report 25:56-57.

Chetelat, R.T. and J.W. DeVerna. 1991. Expression of unilateral incompatibility in pollen of Lycopericon pennellii is determined by major loci on chromosomes 1, 6 and 10. Theor. Appl. Genet. 82:704-712.

Denna, D.W. and H.M. Munger. 1963. Morphology of the bush and vine habits and the allelism of the bush genes in Cucurbita maxima and C. pepo squash. Proc. Amer. Soc. Hort. Sci. 82:370-377.

Erwin, A.T. and E.S. Haber. 1929. Species and varietal crosses in cucurbits. Bul. Iowa Agric. Exp. Sta. 263:344-372.
Finkers, R., A.W. Van Heusden, M.W. Fien, J.A.L. Van Kan, P. Maris, and P. Lindhout. 2007. The construction of a Solanum Habrochaites $\mathrm{LYC}_{4}$ introgression line population and the identification of QTLs for resistance to Botrytis cinerea. Theor. Appl. Genet. 114:1071-1080.

Hiroshi, H. 1963. Cucurbita-crosses: XVI. Flower ages and reciprocal cross-compatibility in $C$. pepo, C. moschata and C. maxima. Japanese Journal of Breeding 13:159-167.

Kanda, T. 1984. Squash. Vegetable seed production technology of Japan elucidated with respective variety development histories, particulars, $\mathrm{p}$. 395-426. In: Shinohara, S. (ed.). Vol. 1. Shinohara's Authorized Agr. Consult. Engineer Office, Nishiooi, Japan.

Loy, J.B. 2004. Morpho-physiological aspects of productivity and quality in squash and pumpkins (Cucurbita spp.). Crit. Rev. Plant Sci. 23:337-363.

McCandless, L. 1998. Geneva releases 'Whitaker' summer squash at the NYS Vegetable Conference. 2011. <http://fls.cals.cornell.edu/OCRPPDF/ 155.pdf $>$.

Munoz, L.C., M.C. Blair, M.C. Dugue, J. Tohme, and W. Roca. 2004. Introgression in common bean $\times$ tepary bean interspecific congruitybackcross lines as measured by AFLP markers. Gemomics, Molecular Genetics \& Biotechnology. $<$ http://www.highbeam.com/doc/1G1-114560997. html $>$.

Parisi, M., M. Iovene, and L. Frusciante. Production and morpho-cytological characterization of $\mathrm{BC}_{2}$ progenies from $5 \mathrm{X} \times 4 \mathrm{X}$ and $4 \mathrm{X} \times 5 \mathrm{X}$ crosses in Solanum. Proc. of the XLV Italian Society of Agricultural Genetics-SIGA Annual Congress Salsomaggiore Term, Italy—26/29, 2001.

Pico, B. Herraiz, J. and F. Nuez. 2000. Lycopersicon chilense-derived bridge lines for introgressing. $L$. peruvianum traits into the esculentum Genome. Tomato Genetics Cooperative (28).

Poysa, V. 1990. The development of bridge lines for interspecific gene transfer between $\mathrm{Lyco}$ persicon esculentum and L. pervianum. Theor. Appl. Genet. 79:187-192.

Rhodes, A.M. 1959. Species hybridization and interspecific gene transfer in the genus Cucurbita. Proc. Amer. Soc. Hort. Sci. 74:546-552.

Robinson, R.W. 1995. Squash and pumpkin. 2010. $<\mathrm{http} / /$ www.ars-grin.gov/npgs/cgc.reports/ squash95.pdf>.
Robinson, R.W. 1999. Rationale and methods for producing hybrid cucurbit seed. J. New Seeds $1: 1-47$.

Saade, R.L. and S.M. Hernandez. 1994. Cucurbits (Cucurbita spp.). 2011.<http://www.hort.purdue. edu/newcrop/1492/cucurbits.html>.

Shifriss, O. 1947. Developmental reversal of dominance in Cucurbita pepo. Proc. Amer. Soc. Hort. Sci. 50:330-346.

Shifriss, O. 1987. Interspecific hybridization. Notes on squash breeding. Cucurbit Genetics Cooperative Report 10:93.

Singh, S.P., H. Teran, H.F. Schwartz, K. Otto, and M. Lema. 2009. White mold-resistant interspecific common bean germplasm lines VCW 54 and VCW 55. Journal of Plant Registrations 3:191-197.

Staub, J. 2002. Cucumis taxonomy, evolution, and interspecific hybridization. 2011. <http:// www.ars.usda.gov/Research/docs.htm?docid$5154 \&$ page $=1 \& \mathrm{pf}=1 \& \& \mathrm{cg}$ id $=0>$.

Stebbins, G.L. 1956. Artificial polyploidy as a tool in plant breeding. Genetics in Plant Breeding. Book-haven Symposia in Biology. p. 37-52.

Wall, J.R. 1961. Recombination in the genus Cucurbita. Genetics 46:1677-1685.

Wang, Y.J., R. Scarth, and C. Campbell. 2002. Interspecific hybridization between Fagopyrum tataricum (L.) Gaertn. and F. esculentum Moench. Fagopyrum 19:31-35.

Wessel-Beaver, L., H.E. Cuevas, T.C. Andres, and D.R. Piperno. 2004. Genetic Compatibility between Cucurbita moschata and C. argyrosperma. Progress in Cucurbit Genetics and Breeding Research, Proc. of Cucurbitaceae 2000, the 8th EUCAPRIA Meeting on Cucurbit Genetics and Breeding, Palacky University, Olomouc, Czech Republic. p. 393- 400.

Whitaker, T.W. and W.P. Bemis. 1964. Evolution in the genus Cucurbita. Evolution 18:553-559.

Whitaker, T.W. and G.N. Davis. 1962. Cucurbits, botany, cultivation utilization. Interscience, New York, NY.

Whitaker, T.W. and R.W. Robinson. 1986. Squash breeding, p. 209-238. In: Bassett, M.J. (ed.). Breeding vegetable crops. AVI Publishing Company, Inc. Westport, CT.

Zack, C.D. and J.B. Loy. 1979. The effect of light and fruit development on internode length in Cucurbita maxima squash. CGC Report 2: 40-41. 